\title{
A Novel Method for Teaching Laser Peripheral Iridotomy and Selective Laser Trabeculoplasty Using Video Instruction and Model Eyes
}

\author{
Jamie Palmer, BS ${ }^{1}$ Geoffrey Nguyen, $\mathrm{BA}^{1} \quad$ Janet Alexander, $\mathrm{MD}^{2}$ Moran R. Levin, MD² \\ Ramya Swamy, MD² \\ ${ }^{1}$ University of Maryland School of Medicine, Baltimore, Maryland \\ 2 Department of Ophthalmology and Visual Sciences, University of \\ Maryland School of Medicine, Baltimore, Maryland

\begin{abstract}
Address for correspondence Ramya Swamy, MD, Department of Ophthalmology and Visual Sciences, University of Maryland School of Medicine, 419 W. Redwood Street, Baltimore, MD 21201 (e-mail: RSwamy@som.umaryland.edu).
\end{abstract}

J Acad Ophthalmol 2022;14:e1-e6.

\begin{abstract}
Keywords

- COVID-19

- laser surgery

- surgical education

- model eyes

- video-based education

Objective The aim of the study is to describe an inexpensive and easily-constructed model eye for the purpose of teaching laser peripheral iridotomy (LPI) and selective laser trabeculoplasty (SLT) to ophthalmology residents.

Methods Easily constructed, inexpensive model eyes were utilized to teach residents SLT and LPI utilizing a remote self-study module. A teaching microscope attachment allowed for video-based instruction and feedback.

Results This model eye, used in conjunction with video modules is an effective lowcost teaching tool for laser surgery among ophthalmology residents. Attending ophthalmologists rated the use of these model eyes using surveys and found them to be appropriate teaching tools that could lead to improved knowledge and translate to better patient care.

Conclusion Our novel method for teaching glaucoma laser surgery allows residents to learn the principles and theory behind common laser procedures while having the opportunity to practice repetitive procedures on low-cost model eyes.
\end{abstract}

Laser peripheral iridotomy (LPI) and selective laser trabeculoplasty (SLT) are common procedures used in the treatment and management of narrow angle, and open angle glaucoma, respectively. For LPI, a small full thickness opening is created in the peripheral iris to allow for equalization of eye pressure between the anterior and posterior chambers. This treats pupillary block and allows aqueous humor to travel from the posterior to the anterior chamber, bypassing the pupil. ${ }^{1}$ SLT selectively treats the pigmented trabecular meshwork cells in eyes with open angle anatomy to enhance the aqueous outflow mechanism and help reduce intraocular pressure in patients with glaucoma and ocular hypertension. ${ }^{2}$

received

March 8, 2021

accepted after revision

July 26, 2021
DOI https://doi.org/

10.1055/s-0041-1741557. ISSN 2475-4757.
The Accreditation Council for Graduate Medical Education (ACGME) requires that each graduate from an accredited residency perform a certain minimum number of LPI (4) and SLT (5) procedures to reach competency before graduation, and residents often perform procedures well in excess of these minimums. Often, residents learn by observing a more senior resident or attending surgeon perform a few procedures before they get to do one themselves. This can lead to potentially increased stress and anxiety among the residents when performing their first few cases. Video-based education and stepwise teaching interventions have been shown to reduce complications and improve resident preparedness by
(C) 2022. The Author(s).

This is an open access article published by Thieme under the terms of the Creative Commons Attribution-NonDerivative-NonCommercial-License, permitting copying and reproduction so long as the original work is given appropriate credit. Contents may not be used for commercial purposes, or adapted, remixed, transformed or built upon. (https://creativecommons.org/ licenses/by-nc-nd/4.0/)

Thieme Medical Publishers, Inc., 333 Seventh Avenue, 18th Floor, New York, NY 10001, USA 
allowing more time for individual review and mastery of each step. ${ }^{3-6}$ However, many programs do not have a formal stepwise training program for laser education. ${ }^{7}$ Here we present a stepwise teaching approach to glaucoma laser surgery which includes self-directed teaching modules with video instruction and affordable model eyes to simulate the surgical experience and allow residents to learn the fundamentals of laser surgery.

\section{Methods}

A self-directed teaching module was created to teach the residents the principles of gonioscopy, SLT, and LPI. Each module was designed to be reviewed in 10 minutes or less and highlights the principles and theory behind the procedures (see Addendum 1). After the residents review this material, they proceeded to watch an instructional video. The video demonstrates laser setup with the model eye, common laser settings, and a demonstration on how to perform SLT and LPI on the model eye. The video can be viewed at this link: "YouTube: Principles of Laser Surgery on Model Eye: LPI and SLT." The module also directs the residents to additional educational resources related to LPI, SLT, and gonioscopy. The residents complete a pre-module survey that assesses their confidence, stress level, and prior experience with laser surgery and a pre-module examination that consists of five questions which assesses their knowledge of functional anatomy related to these procedures, and proper laser settings. Residents were asked to complete two SLT and LPI procedures on the model eyes, and to record the procedure by attaching their cell phones to the Telescope Adaptor Mount (-Fig. 1)

\section{Laser Peripheral Iridotomy}

The Assessment Tool was created using a ping pong ball. The top third of the ball was removed using a precision knife to create an approximately 1.5 " diameter hole. Super glue was then used to secure a single piece of tissue paper over the opening. A center opening was created in the tissue paper to replicate the pupil. Permanent marker dots were drawn in the periphery to represent the iris crypts and mark where the iridotomy should be placed for the module (-Fig. 2).

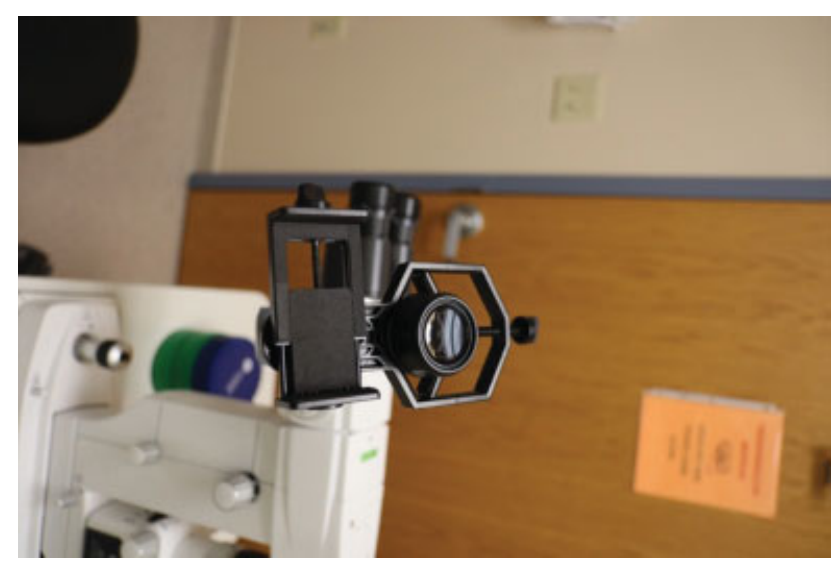

Fig. 1 Telescope Adaptor Mount.

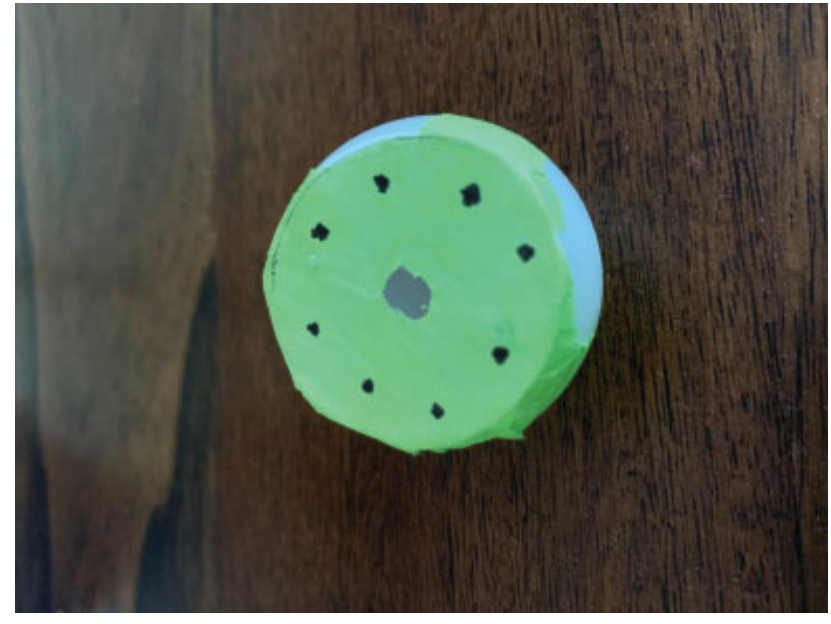

Fig. 2 Laser peripheral iridotomy assessment tool.

A second model eye was created in the same way, but with two layers of tissue paper to replicate a thicker iris.

For each trial, the model eye was secured to the slit lamp with Styrofoam blocks and Velcro (-Fig. 3). Residents were tasked with setting the laser to the appropriate settings (-Table 1) and creating a full-thickness hole at one of the marked points on the single-thickness tissue paper model. They then repeated the iridotomy on the double-thickness tissue paper model for a total of two holes per trial. An image of the model before the iridotomy, as seen through the teaching scope, is seen in -Fig. 4. An image of the model after the iridotomy, as seen through the teaching scope, is seen in - Fig. 5 .

The goal of this simulation was to allow the trainee to practice laser set-up, focus the laser beam with an appropriate offset, and simulate the size and location of a full thickness iridotomy.

\section{Selective Laser Trabeculoplasty}

This assessment tool was also created using a ping pong ball. The top third of the ball was removed using a precision knife to create an approximately 1.5 -inch diameter opening. Super glue was then used to secure a piece of printer paper with

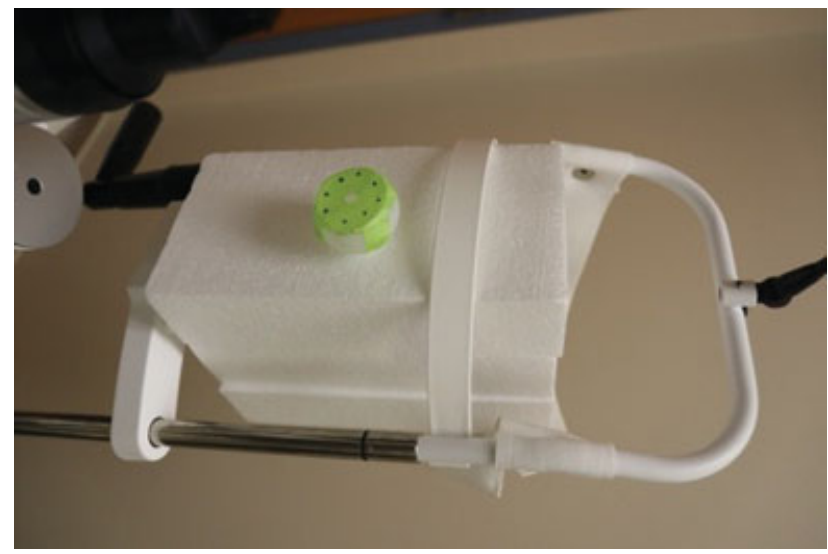

Fig. 3 Laser peripheral iridotomy assessment tool secured to slit lamp. 
Table 1 Laser parameters for laser peripheral iridotomy

\begin{tabular}{|l|l|}
\hline Power $(\mathrm{m} \mathrm{J})$ & $1-6$ \\
\hline Spot size $(\mu \mathrm{m})$ & $50-70$ \\
\hline Number of pulses per burst & $1-3$ \\
\hline
\end{tabular}

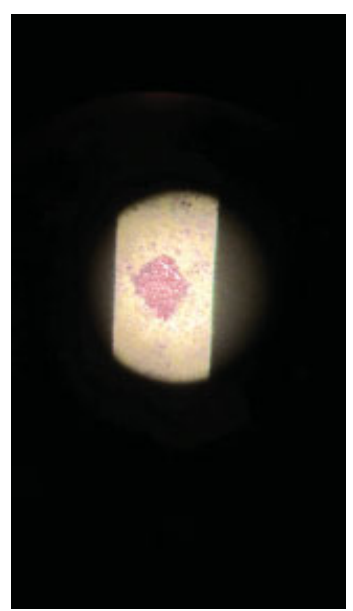

Fig. 4 Laser peripheral iridotomy assessment tool, as seen through the teaching scope, pre-iridotomy.

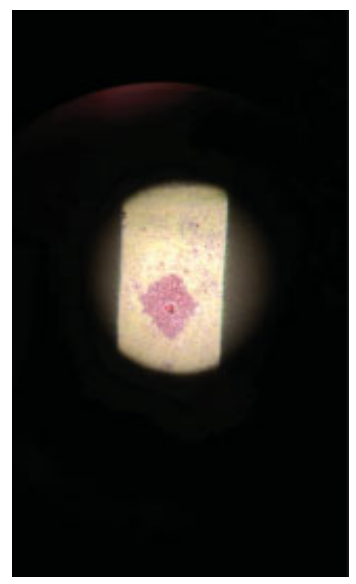

Fig. 5 Laser peripheral iridotomy assessment tool, as seen through the teaching scope, post-iridotomy.

two concentric circles printed on it. A center opening was created in the printer paper to replicate the pupil. The ink circles were representative of the trabecular meshwork (-Fig. 6).

For each trial, the model eye was secured to the slit lamp with Styrofoam blocks and Velcro. Residents were tasked with setting the laser to the appropriate settings and delivering laser pulses to depigment the ink (-Table 2). Each trial was depigmenting half of an ink circle in approximately 50 spots. An image of the model, as seen through the teaching scope, is seen in - Fig. 7.

The goal of this simulation was to teach the trainees how to appropriately space the laser spots and utilize different energy settings to depigment the "trabecular meshwork."

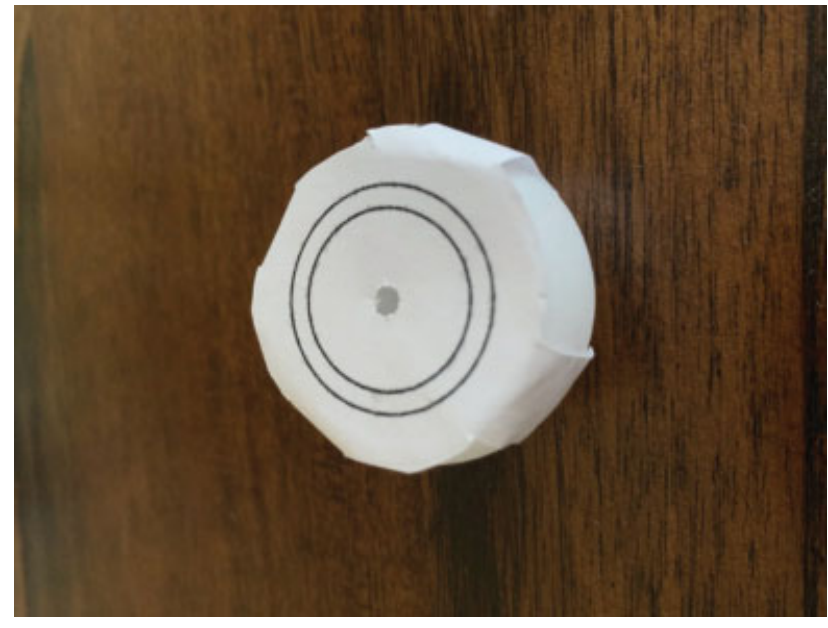

Fig. 6 Selective laser trabeculoplasty assessment tool.

Table 2 Laser parameters for selective laser trabeculoplasty

\begin{tabular}{|l|l|}
\hline Power $(\mathrm{ml})$ & 0.8 \\
\hline Spot size $(\mu \mathrm{m})$ & 400 \\
\hline Pulse duration (ns, nanoseconds) & 3 \\
\hline
\end{tabular}

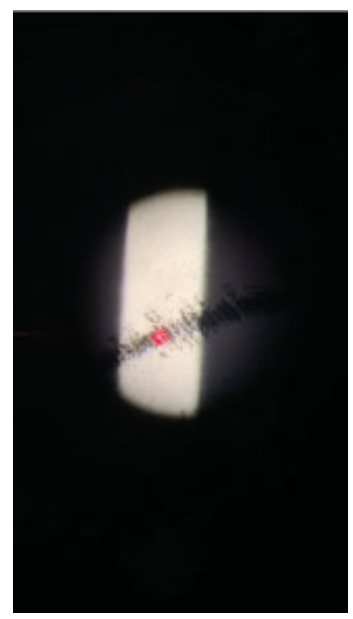

Fig. 7 Selective laser trabeculoplasty assessment tool, as seen through the teaching scope.

Following the module launch, five attending ophthalmologists, including three glaucoma specialists, assessed the validity of this module as an educational tool. The attending physicians viewed the instructional video and associated materials and then answered questions about the appropriateness of the material, suitability of the overall module, and their recommended target audience for the module.

\section{Results}

A total of five questionnaires from attending trials were obtained to assess the validity of this module as an educational tool ( - Fig. 8). They were presented with five statements and 


\section{Independent Skills Module \#2: Laser Peripheral Iridotomy, Selective Laser Trabeculoplasty, Gonioscopy \\ University of Maryland, Ophthalmology}

1. This (module and practice model) is an appropriate teaching tool to teach principals of laser surgery.

\begin{tabular}{|l|c|c|c|c|c|c|c|c|c|}
\hline 1 & 2 & 3 & 4 & 5 & 6 & 7 & 8 & 9 & 10 \\
\hline \multicolumn{2}{|c|}{ Strongly Disagree } & \multicolumn{2}{|c|}{ Disagree } & \multicolumn{2}{|c|}{ Agree } & Strongly Agree \\
\hline
\end{tabular}

2. My students would benefit from practicing with this model before performing this technique on patients.

\begin{tabular}{|c|c|c|c|c|c|c|c|c|c|}
\hline 1 & 2 & 3 & 4 & 5 & 6 & 7 & 8 & 9 & 10 \\
\hline \multicolumn{2}{|c|}{ Strongly Disagree } & \multicolumn{2}{|c|}{ Disagree } & \multicolumn{2}{|c|}{ Neutral } & \multicolumn{2}{|c|}{ Agree } & Strongly Agree \\
\hline
\end{tabular}

3. This module is a suitable tool to teach the residents about the principals of laser and laser set-up.

\begin{tabular}{|l|c|c|c|c|c|c|c|c|c|}
\hline 1 & 2 & 3 & 4 & 5 & 6 & 7 & 8 & 9 & 10 \\
\hline \multicolumn{2}{|c|}{ Strongly Disagree } & \multicolumn{2}{|c|}{ Disagree } & \multicolumn{2}{|c|}{ Agrtral } & \multicolumn{2}{|c|}{ Agree } & Strongly Agree \\
\hline
\end{tabular}

4. The material of these models sufficiently mimics human tissue for educational purposes.

\begin{tabular}{|l|c|c|c|c|c|c|c|c|c|}
\hline 1 & 2 & 3 & 4 & 5 & 6 & 7 & 8 & 9 & 10 \\
\hline \multicolumn{2}{|c|}{ Strongly Disagree } & \multicolumn{2}{|c|}{ Disagree } & \multicolumn{2}{|c|}{ Agree } & Strongly Agree \\
\hline
\end{tabular}

5. Which students do you think would benefit from this training module? (Circle all that apply. If all would benefit, circle "All")

\begin{tabular}{|c|c|c|c|c|c|c|c|c|}
\hline MS 1-2 & MS3 & MS4 & $\begin{array}{c}\text { PGY1 } \\
\text { (Intern) }\end{array}$ & $\begin{array}{c}\text { PGY2 } \\
\text { (Oph 1 } \\
\text { year) }\end{array}$ & $\begin{array}{c}\text { PGY3 } \\
\text { (Oph 2 } \\
\text { year) }\end{array}$ & $\begin{array}{c}\text { PGY4 } \\
\text { (Oph 3 } \\
\text { year) }\end{array}$ & $\begin{array}{c}\text { PGY5+ } \\
\text { (Fellow and } \\
\text { beyond) }\end{array}$ & All \\
\hline
\end{tabular}

Fig. 8 Validity questionnaire distributed to department attending ophthalmologists.

asked to indicate how much they agreed or disagreed with the statement on a scale of $1-10$, with 1 representing strongly disagree and 10 representing strongly agree. The following statements received an average score of 10 :

- "The video presented explained how to set up the laser and use the dials to prepare for each procedure."

- "This (module and practice model) is an appropriate teaching tool to teach principles of laser surgery."

- "My students would benefit from practicing with this model before performing this procedure on patients."

- "This module is a suitable tool to teach the residents about the principles of laser and laser set-up."

The statement "The video through the microscope attachment clearly displays the laser beam and performance of the module" received an average score of 9.6. The statement "The material of these models sufficiently mimics human tissue for educational purposes" received an average score of 8.8.

The attending ophthalmologists were also asked the question, "Which students do you think would benefit from this training module?" All attendings felt that this module would be most beneficial to PGY2 and PGY3 students in their first and second year of ophthalmology residency. However, many saw value for medical students and residents across many years. The distribution of perceived value based on training year is seen in - Fig. 9.

Finally, $100 \%$ of attendings believe that having residents learn the modules and practice on model eyes will lead to faster laser times and/or fewer complications or need for attending takeover or assistance.

\section{Discussion}

Improving surgical education is an important focus area in the field of academic ophthalmology. The amount of clinical and surgical knowledge trainees must obtain to gain to successfully complete their residency training is immense and has increased over the years, while the number of years of training has remained the same. Therefore, a role for innovation is more important than ever. 


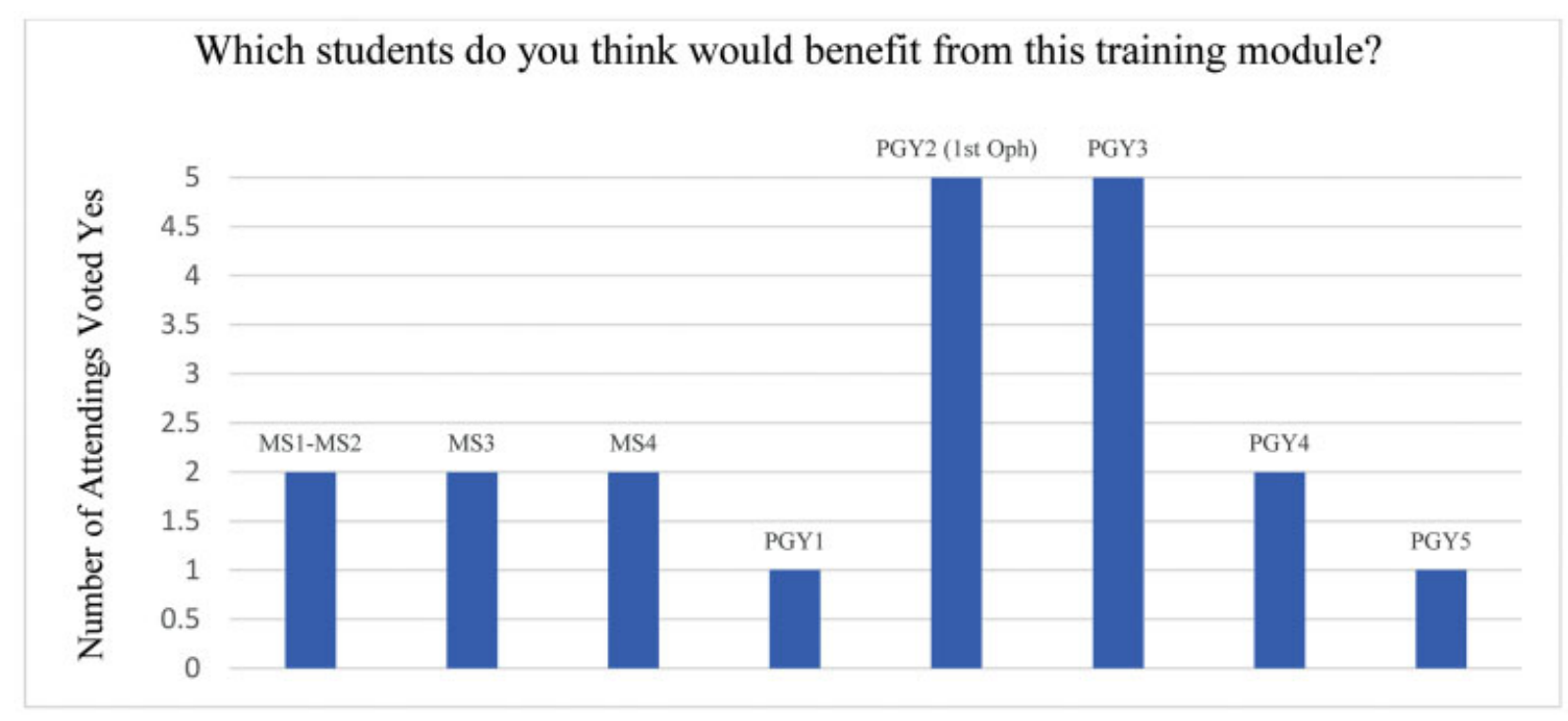

Fig. 9 Distribution of answers about validity of module to students of different training levels.

In prior studies, materials that have been used for laser surgical training include cadaveric animals ${ }^{8}$ and surgical simulators. ${ }^{9}$ Many of these materials are expensive and hard to obtain, and therefore limit the ability to perform several trials during training sessions. The ideal material will help replicate the laser settings used in human tissue, be readily available and inexpensive. Other programs have also designed models that cost under $\$ 40$ and take the average resident or medical student under an hour to construct. ${ }^{10}$ Our model eyes meet many of these important criteria. We estimate that our models cost under $\$ 10$ and take under 30 minutes to construct. There are however some limitations. Due to the size of the model eyes, the lenses typically used in laser procedures (such as the Latina SLT lens and the Abraham Iridotomy lens) cannot be utilized. Similarly, the model eyes do not provide an opportunity to perform gonioscopy or target the SLT laser energy to a structure that mimics the angle.

Total Nd:YAG energy utilized during LPI procedures to obtain full thickness iridotomies decreases with increased levels of training. ${ }^{11}$ The use of higher energy levels is associated with complications such as inflammation, hyphema, corneal decompensation, cataract formation, IOP elevation, retinal detachments, and cystoid macular edema. ${ }^{8,12-14}$ In an effort to reduce complications, improved educational interventions were studied. Studies have shown that video-based education and stepwise teaching interventions reduce complications and improve resident preparedness. ${ }^{5,15}$ Video modules allow residents to pause and rewind instructions as compared with traditional didactic teaching, and stepwise curricula emphasize the importance of mastery of fundamental skills. Competency-based assessment tools have been designed to develop aptitude in these procedures before performing them on real patient. ${ }^{16}$ This module can be adapted to serve as an assessment tool in a full stepwise teaching method before allowing the procedure to be performed on live patients. Students are able to develop confidence and competency with the laser device before adding the pressure of patient care.

The COVID-19 (coronavirus disease 2019) pandemic has created an additional challenge to hands-on training. To maintain social distancing, we were unable to bring residents together in the same physical space to demonstrate, teach, and observe. The self-learning modules allowed the trainees to learn the relevant information and practice the laser treatments at their own pace.

In conclusion, our novel method for teaching glaucoma laser surgery allows residents to learn the principles and theory behind common laser procedures, while having the opportunity to practice repetitive procedures on low-cost model eyes. Prior studies in ophthalmology have demonstrated that a stepwise approach is helpful in mastering other surgical techniques. Attending surveys have helped provide insight and feedback from experts in the field that this module is a useful tool to help teach laser surgery in a stepwise approach.

\section{Conflict of Interest}

None declared.

\section{References}

1 “Laser Peripheral Iridotomy.". EyeWiki, 4 Apr. 2020, Accessed August 1, 2020 at: eyewiki.aao.org/Laser_Peripheral_Iridotomy

2 Jha B, Bhartiya S, Sharma R, Arora T, Dada T. Selective laser trabeculoplasty: an overview. J Curr Glaucoma Pract 2012;6 (02):79-90

3 Lorch AC, Kloek CE. An evidence-based approach to surgical teaching in ophthalmology. Surv Ophthalmol 2017;62(03): 371-377

4 Kloek CE, Borboli-Gerogiannis S, Chang K, et al. A broadly applicable surgical teaching method: evaluation of a stepwise introduction to cataract surgery. J Surg Educ 2014;71(02):169-175

5 Mishra K, Mathai M, Della Rocca RC, Reddy HS. Improving resident performance in oculoplastic surgery: a new curriculum using surgical wet laboratory videos. J Surg Educ 2017;74(05):837-842 
6 Pantanelli SM, Papachristou G, Callahan C, Chen M, Khalifa Y. Wet Lab-Based Cataract Surgery Training Curriculum for the PGY 2/ PGY 3 Ophthalmology Resident. 2018;14:10782

7 Wen JC, Rezaei KA, Lam DL. Laser peripheral iridotomy curriculum: lecture and simulation practical. MedEdPORTAL 2020;16:10903

8 Robin AL, Pollack IP. A comparison of neodymium: YAG and argon laser iridotomies. Ophthalmology 1984;91(09):1011-1016

9 Dubois P, Rouland JF, Meseure P, Karpf S, Chaillou C. Simulator for laser photocoagulation in ophthalmology. IEEE Trans Biomed Eng 1995;42(07):688-693

10 Kylstra JA, Diaz JD. A simple eye model for practicing indirect ophthalmoscopy and retinal laser photocoagulation. Digit J Ophthalmol 2019;25(01):1-4

11 Jason PK, Emily MZ, Leona D, Joanne CW. Resident-performed laser peripheral iridotomy in primary angle closure suspects, and primary angle closure glaucoma. Clin Ophthalmol 2017; 11:1871-1876
12 American Academy of Ophthalmology. Laser peripheral iridotomy for pupillary-block glaucoma. Ophthalmology 1994;101 (10):1749-1758

13 Alimanović-Halilović E Complications in the posterior eye segment after Nd-YAG laser capsulotomy. Med Arh 2004;58(01):7-9

14 Ranta P, Tommila P, Kivelä T Retinal breaks and detachment after neodymium: YAG laser posterior capsulotomy: five-year incidence in a prospective cohort. J Cataract Refract Surg 2004;30 (01):58-66

15 Gershuni V, Woodhouse J, Brunt LM. Retention of suturing and knot-tying skills in senior medical students after proficiencybased training: results of a prospective, randomized trial. Surgery 2013;154(04):823-829

16 Wentzell DD, Chung H, Hanson C, Gooi P. Competency-based education assessment tools for laser capsulotomy, peripheral iridotomy, and selective laser trabeculoplasty. Ophthalmol Glaucoma 2019;2(03):179-187 